to the causation and treatment of abnormality. The Combined Textbook is a successful example of a 'larger volume'. Many medical students will find it easy, even compulsive, reading even though the standard of many of the chapters is that of the membership examination of the Royal College of Obstetricians and Gynaecologists rather than that of the M.B. B.S. This is particularly true of the excellent chapters on reproductive science-epidemiology, physiology, endocrinology, blood coagulation and genetics. The chapters on pregnancy hypertension, pain relief and ultrasonic diagnosis are also of high quality. The gynaecological section is relatively brief, compared with the obstetric section but is adequate for the medical student. All chapters have references and well chosen lists of 'further reading'.

Much of the writing is new but in a few places it is apparent that this is the ninth edition of a work first published in 1923. In a few places new sections have been inserted into older material; thus, in chapter 3 consecutive tables show different mean diameters for the pelvic brim. Much more importantly the chapter on labour does not convey the attitudes of modern labour ward practice. Modern practice is describedno important points are omitted-but the emphasis is on the mechanics of labour as opposed to the physiology of labour. Space is used to describe the preparation of a room for home confinement and the details of diet in labour, while relatively little space is given to fetal heart monitoring and the assessment of fetal distress. The section on induction is disappointing; the reasons for induction of labour are inadequately discussed, even at undergraduate level, and the importance of the favourable cervix under-emphasized. The section on the induction of abortion should mention Utus paste if only to condemn this obsolete preparation.

In spite of these criticisms, this edition of the Combined Textbook is probably the best undergraduate book on obstetrics and gynaecology in Britain. Unfortunately the price will make it impossible for many students to own a copy and medical school libraries, short of funds, will have to chain their copy to the shelf.

\section{Current Topics in Connective Tissue Diseases}

Edited by P. J. L. Holt. Pp. 200, illustrated, hard cover. Churchill Livingstone, 1975. £6.50.

The Editor explains that the contents of this volume reflect both his own interests and fields where progress is occurring. The result is a scrappy book; chapters cover anything from the physiology of the synovial cell to the way drugs act and there is no connecting theme, each chapter being an essay in its own right.

The authors are internationally distinguished. The book is printed on gloss paper, the many illustrations are excellent and the bibliography extensive.

We found the chapters on physiology of the synovial cell, joint cartilage and immunology of inflammation at the cellular level clear and up to date, though of only passing interest to the clinician. The chapter on rheumatoid factor may interest the clinician but sadly is somewhat out of date inasmuch as it does not deal with the new tests such as Rheumatoid Arthritis Haemagglutination (RAHA) which has replaced the cumbersome Waler-Rose test in clinical laboratories.

There is nothing much new in the chapter on assessment of the rheumatoid hand. The surgical authors claim that results of surgery are promising. The physician has heard this before.

The only misprint we found is that Brufen is said to be the trade name for Ibufenac (Ibuprofen) in the chapter on antirheumatic drugs.

Some of the nine chapters in this book will interest some people but it is difficult to guess at what audience, other than the editor, the book is aimed.

\section{Dental Problems in Medical Practice}

By Richard CoOper. Pp. 284, soft cover, illustrated. William Heinemann, London, 1976. £5.75.

It is not often that a doctor finds himself faced with the necessity to undertake a dental procedure. The author of this book has covered such eventualities, although one cannot suppress a pang of sympathy for the patient in such circumstances.

Dentistry impinges on medical practice much more commonly when the dental surgeon requires advice from a medical colleague about a mutual patient. This book has all the answers both for the doctor and the dental surgeon in such cases.

Pharmacology is obviously a particular interest for the author. Throughout the book this subject is well covered and accurate, although most dental surgeons today would give metronidazole (flagyl) a higher place in the treatment of acute ulcerative gingivitis. An important opportunity has been missed in that there is no mention of tetracycline staining of teeth due to the use of this group of antibiotics during the period when the teeth are calcifying. The use of this antibiotic for herpetic ulceration in children is even advocated on page 103 and is deplored by the reviewer.

The author attempts to make the book a complete 'minitextbook' of dentistry for consumption by doctors. This very attempt may have inadvertently produced a useful reference pitched at a suitable level for other groups such as dental nurses, dental auxiliaries and dental hygienists or even for nurses and health visitors. U.K. dental nurses in N.H.S. practice would be the first to notice reference to N.H.S. charges where the amounts quoted are already outdated by new regulations. A useful addition could have been by reference to instances where lack of dental knowledge on the part of doctors could be to the detriment of the treatmen of their patients, for example: the chronic abscess pointing externally on the face over the body of the mandible treated unsucessfully by antibiotics, and where the causal septi\& carious lower molar tooth was not even suspected or looked for.

The author has attempted a difficult task in a small, practical, well illustrated and readable book. Few doctors and medical students would not benefit from reading it from cover to cover. Dental surgeons would also find it interesting and would almost certainly learn something new.

\section{Fundamental Aspects of Metastasis}

Edited by Leonard Weiss. Pp. xi +443 , hard cover, illustrated. North-Holland Publishing Co., Amsterdam, 1976. US \$53.95 (Dfl. 140.00).

This book on metastases is welcome as there are very few books on the subject. It is based on a number of papers given at a meeting in 1975 on Metastatic Mechanisms. A clear and fresh account is given; most other books have dealt with the subject from a different viewpoint. The book is valuable for people seeing large numbers of cases with secondary deposits, or working in departments of oncology who wonder why patients with an apparent similar tumour may produce either no, or a widely differing distribution of, metastases.

The main feature of the book is on experimental work with no part on therapy. It begins with a section on how the surface properties of malignant cells differ from normal ones. This is followed by a discussion on the changes in malignant cells when stopped by vascular endothelium, together with the effects of normal cells in the blood stream on malignant cells. The reaction of the rest of the body to tumours is then discussed, dealing with the interaction of malignant cells with the immune system of the body. The next section consists of a series of observations dealing with studies on the actual metastases, namely how to quantitate them in man and why they are more common in some organs. 
The chapters are well written and conclude with a study of metastases in man, there is a chapter on the diagnosis of metastases by various $\mathrm{X}$-ray techniques, including scans. The final chapter deals with the usefulness of measuring various antigen; such as carcino-embryonic antigen (CEA). Unfortunately the estimation of such antigen in early detection of tumour has not yet proved very reliable, but is obviously a promising field for future research. So far, the only success in this field is the use of CEA in monitoring the progression of carcinoma of the colon.

This book is excellent for the person who is interested in metastases and wishes to be stimulated into thinking about possible reasons for their behaviour.

\section{Health Care in a Changing Setting: the U.K. Experience}

Ciba Foundation Symposium 43 (new series). Pp. viii + 188, hard cover, illustrated. Excerpta Medica, Amsterdam, 1976. Dfl 37.00, U.S. \$14.25.

It is not given to us all to become famous, but in this busy world there are few who, metaphorically speaking, need 'waste their sweetness on the desert air' or, in less poetical language, 'lead a useless life'. So begins the 1901 edition of Mrs Beeton's Cookery Book. I am sure that it was in the minds of the C.I.B.A. Foundation when they arranged their symposium on 'Health Care in a Changing Setting: the U.K. Experience' December 1975 (published August 1976), to ensure that the deliberations of the participants were not so wasted. To return to Mrs Beeton, 'In the hands of a good cook a joint (with the exception of veal) will always yield enough gravy to serve with it, but for game, poultry and other dishes, it must be made'. It was decided that Ruth Porter (organizer) and David W. Fitzsimons should edit the proceedings of this C.I.B.A. Foundation symposium. The reader has to decide how far their working material was veal, game or poultry or the viands with a more substantial gravy yield.

Certainly there are several solid contributions such as that of Leslie Paine, House Governor and Secretary of the Bethlem Royal Hospital, 'In a nutshell', he says, 'I am suggesting that our new system has perhaps overlooked the single fact that patients come to health services to be treated and not administered'. Breath-taking stuff for the new generation reared on McKinsey and Co. Inc.

The current demoralization of doctors could not be better exemplified than by the contribution of Professor Peter Huntingford, who confirmed that he had no role. When asked the implications of rejecting the role of the doctor as the leader of the team, he replied, 'I am unable to answer questions such as "what do you like done in this situation?" It leads to tensions and anxieties amongst my junior staff. I regret that for their sakes, but I am not going to stop rejecting the role of doctor; my junior colleagues must come to terms with their own anxieties'. One welcomes the intentions of C.I.B.A. to invite groups of distinguished people to come together to discuss defined subjects and to make constructive comments. It is more difficult to see their purpose in preparing a symposium which incorporates papers of considerable merit upon such disparate subjects as change, re-organization, university health, society, shortened hospital stay, the nurses contribution, quandaries of the health visitor, academic research, cancer and postgraduate training. It is the reviewer's sincere belief that had a medical Mrs Beeton been their adviser she would have thought out her symposium in such a way, that it concentrated upon one or at most three of these subjects rather than spread it over a dozen. If it was a main purpose of the symposium to prepare a subsequent report which might be influential in respects of the changing health needs in the U.K., then there is little doubt that the time of the busy and distinguished people who were the participants would have been better used in the consideration of a more clearly defined area of need. Their subsequent report might then have had considerable impact for there is no doubting of the talent of the contributors. As it is the cooks have had to work very hard to make the gravy.

\section{Hematologic Diseases. New Directions in Therapy}

By Peter Curt Ungaro. Pp. 255, soft cover. Henry Kimpton Publishers, London, 1976. £7.50.

This is an interesting book in a delightful style and format, which sets out to describe the management of blood disorders. Not surprisingly in a single-author book some sections are much better than others. There is an excellent account of management of haematological malignancies, although the section on acute myeloid leukaemia largely ignores problems of sterile environments for patients and related measures to reduce the incidence of infection.

What the author calls 'building block deficiences' is discussed in nine pages which is not much when it embraces iron, $B_{12}$, folate, as well as the minor deficiencies such as pyridoxine, ascorbate, etc. Two short paragraphs are all that are devoted to parenteral iron administration. There is no attempt to discuss particular problems in childhood or during pregnancy. Perhaps there are no such problems in the U.S.A., and these are problems of developing and declining countries.

Nevertheless, this is in many respects an admirable book which students at all levels will find not only useful but a pleasure to read.

\section{An Introduction to Mechanisms in Pharmacology and Thera-} peutics

By Howard Rogers, Roy SPECTOR, with contributions by John Trounce. Pp. 411, illustrated, hard cover. William Heinemann Medical Books Ltd, London, 1976. £7.50.

This book is welcome at a time when there are increasing demands on teachers of pharmacology to interpret the actions of drugs in terms of our growing understanding of molecular biology. It is not a book of systematic pharmacology, nor does it claim to be, but attempts, largely successfully, to explain the mechanisms of action of drugs in terms of cell biology on one hand, and the needs of clinical medicine on the other. There are a few irritating errors in drug names and typography, but that apart, it is firmly recommended, particularly to honours B.Sc. pharmacology candidates, and to those doing clinical studies and who wish to probe more deeply into the actions of those drugs which they are learning to use.

\section{Modern Topics in Rheumatology}

Edited by Graham R. V. Hughes. Pp. $200+$ viii, hard cover, illustrated. William Heinemann Medical Books Ltd, London, 1976. £8.00.

In his foreword Graham Hughes says that editing this book was 'surprisingly enjoyable'. Well, the same can be said of reading it. Surprising, because rheumatology review books nowadays tend to contain long articles dealing with immunological or biochemical topics in great depth: valuable for those preparing papers on the subject themselves, but dull for the general reader. By contrast, Hughes has persuaded most of his authors to keep within 3000 words (not rigidly: George Nuki's outstanding review of gout and purine metabolism is rightly allowed more space) and the result is a series of papers which read like expanded leaders from the medical weeklies. The shortness of the chapters has allowed twenty-three to be included in the 200 pages, and the authors -well chosen from both sides of the Atlantic-between them cover all the important growing points in rheumatology.

This book will probably have most appeal for the practising or trainee rheumatologist. It can be read from cover to 